\title{
The Influence of Tensile Rate on the Tensile Fracture Process of PA6
}

\author{
Jun DAl ${ }^{1, a}$, Yu-Zhu XIONG ${ }^{1,2, b,{ }^{*}}$, Xin LI $^{1, \mathrm{c}}$, Ling-Feng CUI ${ }^{1, \mathrm{~d}}$ \\ 1 College of Materials and Metallurgy, Guizhou University, Guiyang 550025; \\ 2 Guizhou Key Laboratory for Mechanical Behavior and Microstructure of Materials, Guiyang \\ 550025, Guizhou, China \\ a827094387@qq.com, b932271187@qq.com, cergouli1992@163.com, d869997899@qq.com \\ * Yu-Zhu XIONG
}

Keywords: Nylon 6, Tensile rate, Aggregation structure, Double yield.

\begin{abstract}
In this paper, we researched the influence of tensile rate on the tensile fracture process of PA6. The results showed that with the increase of tensile rate, the yield strength of PA6 was on the rise, and the elongation at break was on the decline. The elongation at break declined sharply when the tensile rate increased to $50 \mathrm{~mm} / \mathrm{min}$, it' s because that under the tensile rate of $50 \mathrm{~mm} / \mathrm{min}$, the PA6 crystallinity decreased obviously after stretching, the lattice was damaged seriously, and there was also a sharp decline in capacity of molecular chain segments together with plastic deformation. In low-speed PA6 tensile process, for the two peak valleys of seven sates crystallinity changing curve just respectively corresponded to the tensile states when two yield occurred in tensile process, we thought there was a certain relationship between double yield and crystal destruction. The phenomenon of double yield in low-speed tensile process might be accompanied with the destruction of the $\gamma$ crystal.
\end{abstract}

\section{Introduction}

For the viscoelasticity of polymer materials and the close relationship among mechanical property, internal structure, and external factors[1-8], it' s very important to research the influence of tensile rate to aggregation structure, mechanical property and partial response[9]. Chang' an Cai[10] studied the strain rate sensitivity of PBT, and finding the tensile strength of polymer increased with the increase of strain rate. High sensitive area was corresponded to the low tensile rate, medium sensitive area was corresponded to the medium stretching rate, and low sensitivity area was corresponded to stretching rate at high speed. Jie Yu [11] had studied the influence of loading rate on mechanical properties of PVC. When the tensile load speed was low, the size of the radiation extension area is larger, which was caused by controlled expansion of crack. By contrast, when the tensile load speed was high, the size of area is smaller, which was caused by rapid expanding of crack. With the increase of stretching rate, the movement of the PVC molecular chain increasingly was difficult, macromolecular configuration stretch smaller, therefore, the deformation produced by distance change between atoms became greater. As deformation rate increase, the essential force that made the sample produce the same deformation increased, and resulted in that the strength of the material showed higher. Jinjuan Fan[12] studied fracture microstructure of silicone rubber under different tensile rates, they found that under different tensile rates, the microscopic structure of crack propagation showed a parabolic characteristics mainly. With the increase of stretching rate, the depth and length of the parabola increased, as well as fracture surface was rough. When the stretching rate increased to a certain degree, smooth zone appeared secondary crack. PA6 belongs to semi crystalline polymer with a variety of crystal forms in the crystalline part, and all kinds of crystal forms can mutual transform under certain conditions [13-14]. In this paper, we researched the influence of tensile rate on the tensile fracture process of PA6, expecting to provide useful research foundation for the engineering practice and application of PA6. 


\section{Materials and Methods}

Sample and Tensile Test. In this research, we used injection molding machine (PL860/290v, Wuxi Haitian Plastic Machinery Co., Ltd) to make the PA6(M3400, Guangdong Xinhui Meida Nylon Co., Ltd.) samples which were stretched by universal testing machine(WDW-10,Ji' nan Naier Test Machinery Co., Ltd). This experiment with reference to GB/T 10402-2006. The temperature level of $23^{\circ} \mathrm{C}$ was applied to tensile process and tensile rates, respectively, the tensile speeds were about to $10 \mathrm{~mm} / \mathrm{min}, 20 \mathrm{~mm} / \mathrm{min}, 50 \mathrm{~mm} / \mathrm{min}, 100 \mathrm{~mm} / \mathrm{min}, 200 \mathrm{~mm} / \mathrm{min}, 500 \mathrm{~mm} / \mathrm{min}$. After the tensile process which tested by using different samples with $10 \mathrm{~mm} / \mathrm{min}$ tensile rate presented seven stages as shown in figure 5, we aborted the process. Then we kept the corresponding states and cut sample for testing.

Differential Scanning Calorimetry(DSC). The crystalline was analyzed by DSC (Q10, TA Instruments, USA). We cut the samples into $5 \mathrm{mg}$, and tested them under nitrogen atmosphere protection with $10^{\circ} \mathrm{C} / \mathrm{min}$ speed from $25^{\circ} \mathrm{C}$ up to $250^{\circ} \mathrm{C}$. The crystalline was estimated by using the equation

$$
X c=\frac{\Delta H}{\Delta H_{100 \%}} \times 100 \%
$$

Where $\mathrm{Xc}$ is the crystalline, $\Delta \mathrm{H}$ is the melting enthalpy. $\Delta \mathrm{H} 100 \%$ is the melting enthalpy when crystalline is $100 \%$, in this paper we use $\Delta \mathrm{H} 100 \%=190 \mathrm{~J} / \mathrm{g}$.

X-ray Diffraction (XRD). The XRD (X'Pert PRO, PANalytical B.V) which was copper target, test angle is about $10^{\circ}<2 \theta<400^{\circ}$ with $20 /$ min scan rate and $40 \mathrm{kv}$ accelerating voltage. At same time, we used Jade to do peak separation method and curve-fitting analysis.

Nuclear Magnetic Resonance Spectroscopy (NMR). At room temperature, the main parameters ${ }^{13} \mathrm{C}$ resonant frequency of the NMR (AVANCE III; Bruker Corporation) was $47.47 \mathrm{MHz}$. The CP (cross-polarization) time was $1.5 \mathrm{~ms}$, rotational speed was $4 \mathrm{kHz}$, and relaxation time was $6 \mathrm{~s}$. We could obtain both crystalline area and amorphous area signal at the same time though ${ }^{13} \mathrm{C}$ CP/MAS/HPDEC (cross-polarization, magic angle spinning and high-power decoupling method) method.

\section{Results and Discussion}

\section{The Influence of Tensile Rate on PA6 Aggregation Structure and Tensile Property}

The XRD curve of PA6 was shown in Fig. 1. The curve without stretching was absolutely sharp and the characteristic peak was obvious which meant the crystal structure was structured. When the tensile rate was $10 \mathrm{~mm} / \mathrm{min}$, compared with the one without stretching, the curve of characteristic peak was move to left, which meant that lattice distance increased slightly. But when the stretching rate increased to $50 \mathrm{~mm} / \mathrm{min}$, the XRD curve was smooth and the characteristic peak disappeared, which meant the crystal structure was damaged obviously. 


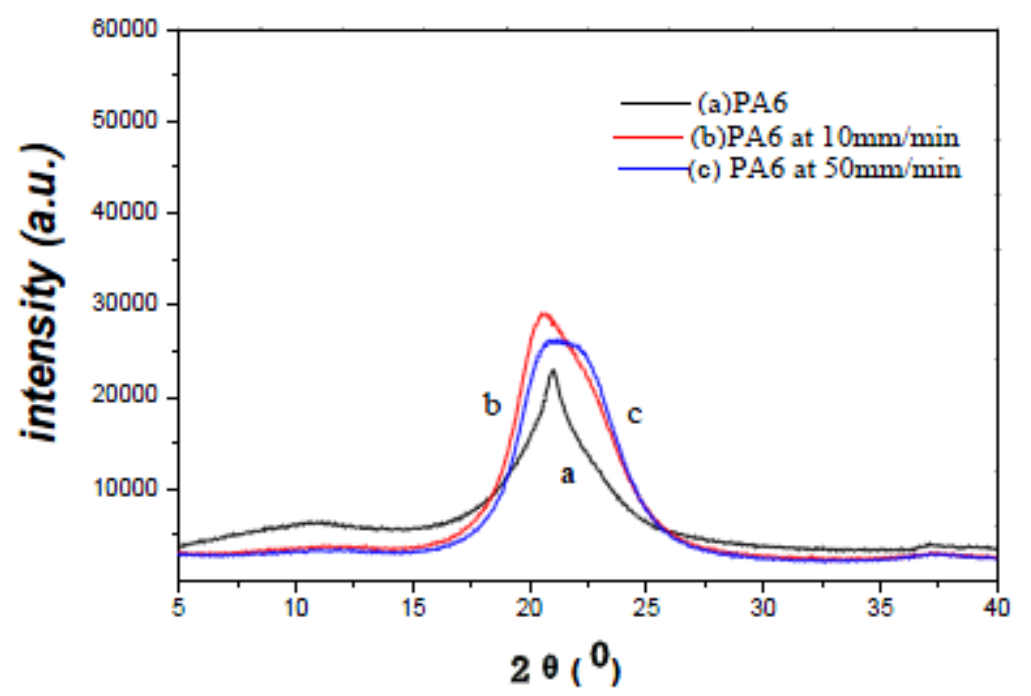

Fig. 1. X-ray diffraction patterns of pure PA6 with different tensile rate a:No tensile; b: tensile rate $10 \mathrm{~mm} / \mathrm{min}$; c: tensile rate $50 \mathrm{~mm} / \mathrm{min}$

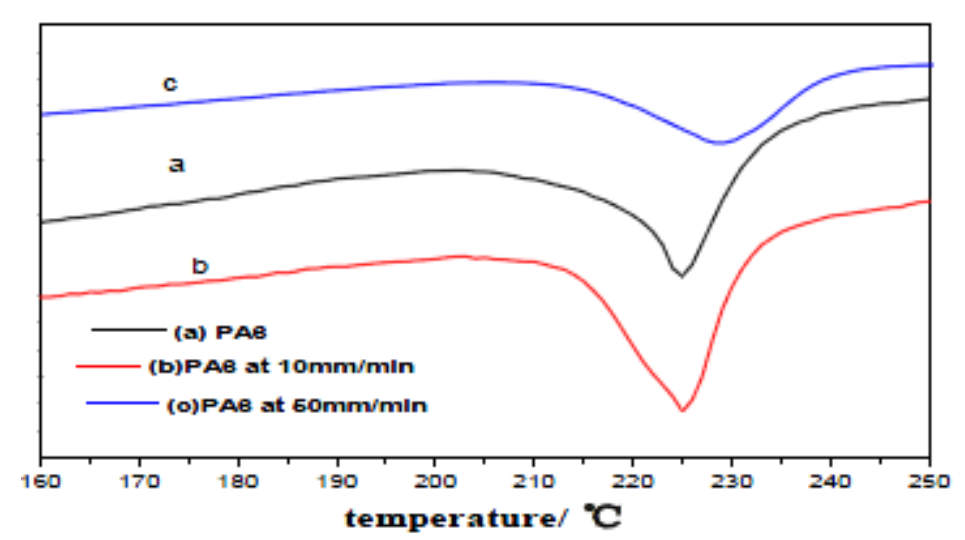

Fig. 2. DSC curves of PA6 with different tensile rate a: No tensile; b: tensile rate $10 \mathrm{~mm} / \mathrm{min}$; c: tensile rate $50 \mathrm{~mm} / \mathrm{min}$

Table 1. DSC results of PA6 with different tensile rate

\begin{tabular}{|l|c|l|}
\hline Sample & $\Delta H /(\mathrm{J} / \mathrm{g})$ & $X c / \%$ \\
\hline PA6 & 63.86 & 33.61 \\
\hline PA6 at $10 \mathrm{~mm} / \mathrm{min}$ & 66.58 & 35.04 \\
\hline PA6 at $50 \mathrm{~mm} / \mathrm{min}$ & 36.71 & 19.32 \\
\hline
\end{tabular}

Fig. 2. and Table 1. showed that the crystallinity of PA6 after tensile fracture was higher than the one without stretching when tensile rate was $10 \mathrm{~mm} / \mathrm{min}$. But the when tensile rate was $50 \mathrm{~mm} / \mathrm{min}$, crystallinity of PA6 after tensile fracture decreased significantly. By the increase of stretching rate, PA6 lattice damage was serious and lattice distance was increased gradually with the decrease of crystallinity. 


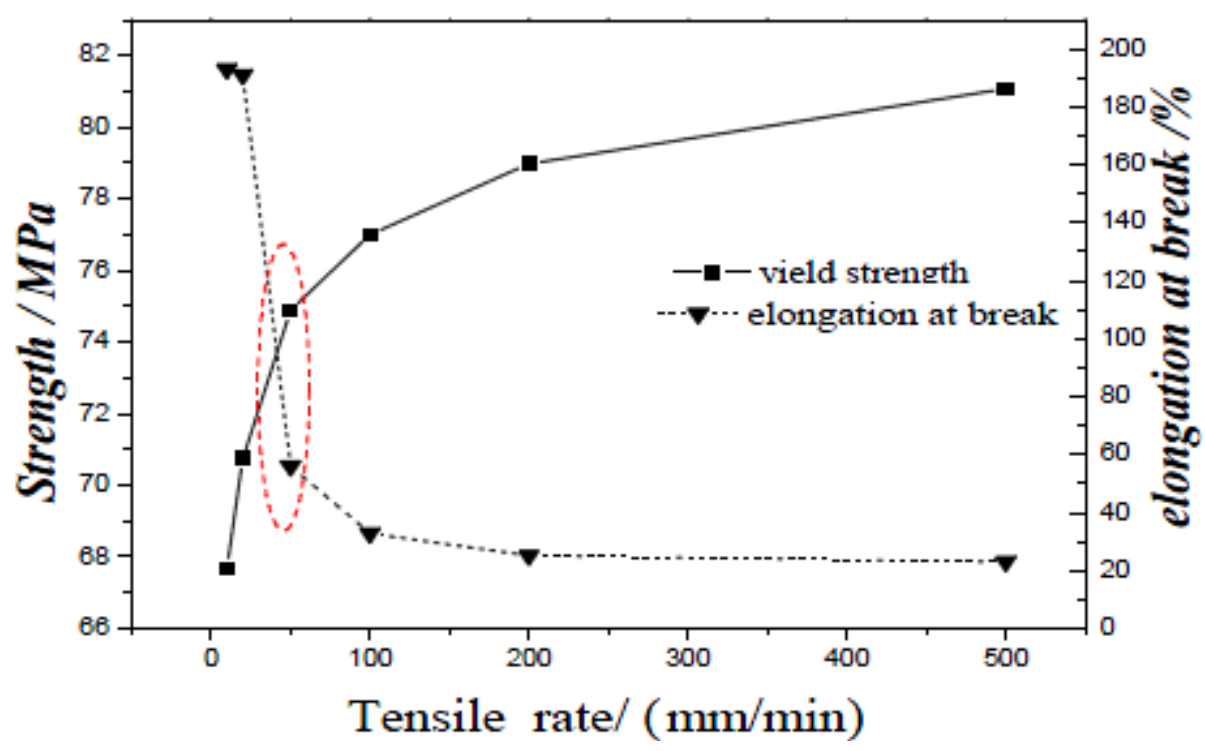

Fig. 3. Relationship between yield strength and elongation at break of stretch rate.

From Fig. 3, it can be seen that the yield strength of PA6 was on the rise with the increase of stretching rate, which was in line with the theory of Eyring on the linear relationship between the yield strength and tensile rate. However, the elongation at break decreased with the increasing of tensile rate. The findings showed that when the tensile rate was $50 \mathrm{~mm} / \mathrm{min}$, the crystallinity of PA6 after tensile fracture decreased significantly, lattice damage was serious and there was also a sharp decline in capacity of molecular chain segments together with plastic deformation. All above factors were caused by the sharp decrease of elongation at break.

\section{The Phenomenon of Double Yield in Low-Speed Tensile Process}

Fig. 4 shows the load-displacement curves of PA6 under different tensile rates. There were always presented double yield phenomenons when the tensile rates were $10 \mathrm{~mm} / \mathrm{min}$ and $20 \mathrm{~mm} / \mathrm{min}$. After the local necking appeared in the first yield deformation, we continued stretching the PA6 sample, and finding that the sample occurred second local necking at the same area of the first local necking again until the necking fracture. There was no double yield phenomenon when tensile rate was more than $50 \mathrm{~mm} / \mathrm{min}$. The polymer in the same local internal structure was with the increase of the action time took on superimposing changing process. Butler[15-16] studied it though small angle and wide angle X-ray scattering synchronization technology, and finding that polymer for the first yield could be restored which corresponded to the imperceptible chain slip. But the polymer could not be restored at second yield which corresponded to the lamellae rupture caused by Coarse chain slip. Although the mechanism of double yield phenomenon had not yet completely clear, we could affirm that the occurrence of double yield was inevitably related to the aggregation structure. In this paper, after the tensile process which tested by using different samples with $10 \mathrm{~mm} / \mathrm{min}$ tensile rate presented seven stages as shown in Fig. 5, we aborted the tensile process and studied the relationship between aggregation structure and double yield at this stage. 


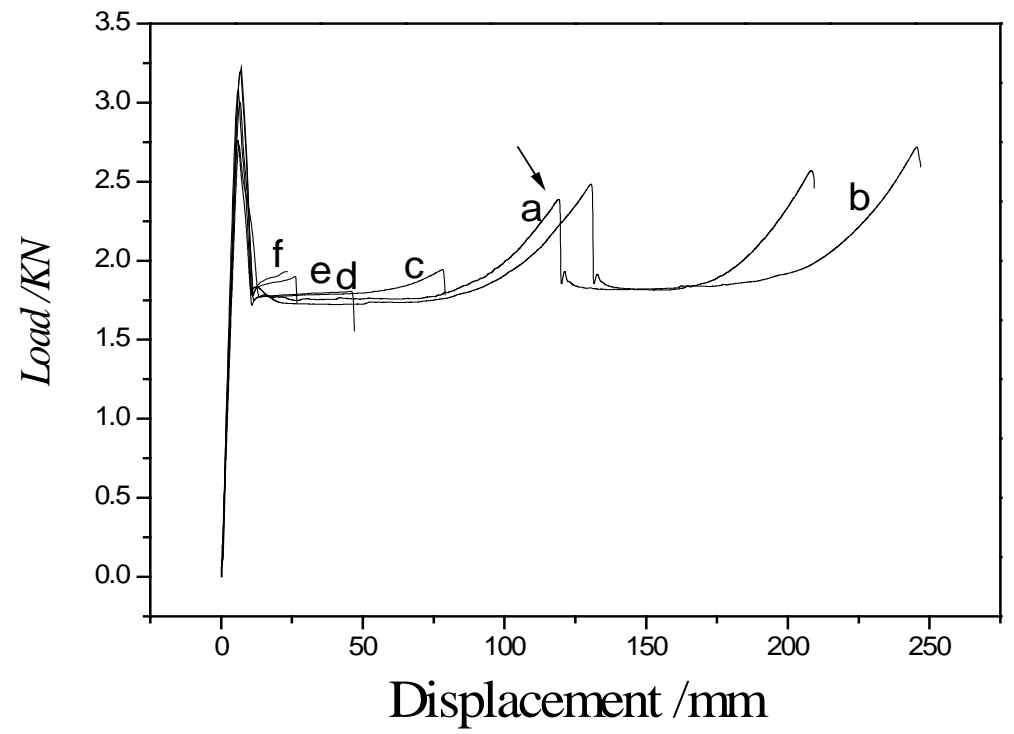

Fig. 4. Load-displacement curves of PA6 at different tensile rate a. $10 \mathrm{~mm} / \mathrm{min} ;$ b. $20 \mathrm{~mm} / \mathrm{min} ;$ c. $50 \mathrm{~mm} / \mathrm{min} ; \mathrm{d} .100 \mathrm{~mm} / \mathrm{min} ; \mathrm{e} .200 \mathrm{~mm} / \mathrm{min} ;$ f.500mm $/ \mathrm{min}$

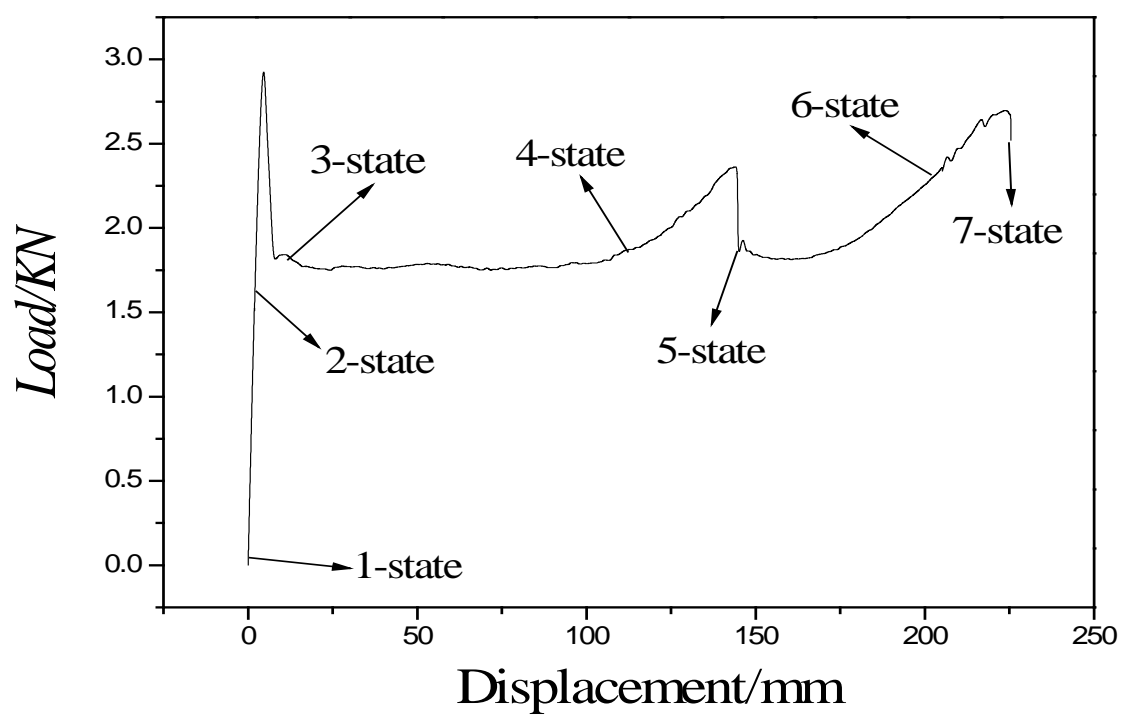

Fig. 5. Different tensile strain state in load-displacement curves of PA6 at 10mm/min tensile rate: (1)1-state;(2)2-state;(3)3-state;(4)4-state;(5)5-state; (6)6-state; (7)7-state

Fig. 6. shows the XRD, from tensile state 1 to 7, the sharp degree of PA6 crystal characteristic peak reduced gradually. It could be seen that the PA6 crystal structure was changed constantly with continuous tensile process and the crystal structure was broken. We treated the XRD figures of seven different tensile states by Sub-peak fitting method [17]. Fig. 7. shows that in the spectrogram of PA6,the $2 \theta$ values were about $20^{\circ}$ and $23^{\circ}$. There were two characteristic peaks of $\alpha$ crystal and respectively corresponded to the crystal plane (200) and (002). The $2 \theta$ value was $21^{\circ}$, the $\gamma$ crystal characteristic peak corresponded to the crystal plane (200). The result of Sub-peak fitting was shown in Fig. 8. At the stages 1, 2, 3 and 4 there were not double yield occurred yet, $\alpha$ crystal accounted for $75 \%$ and $\gamma$ crystal accounted for 25\%. But the stages 5, 6 and 7 presented phenomenon of double yield already, the $\gamma$ crystal was totally disappeared. 


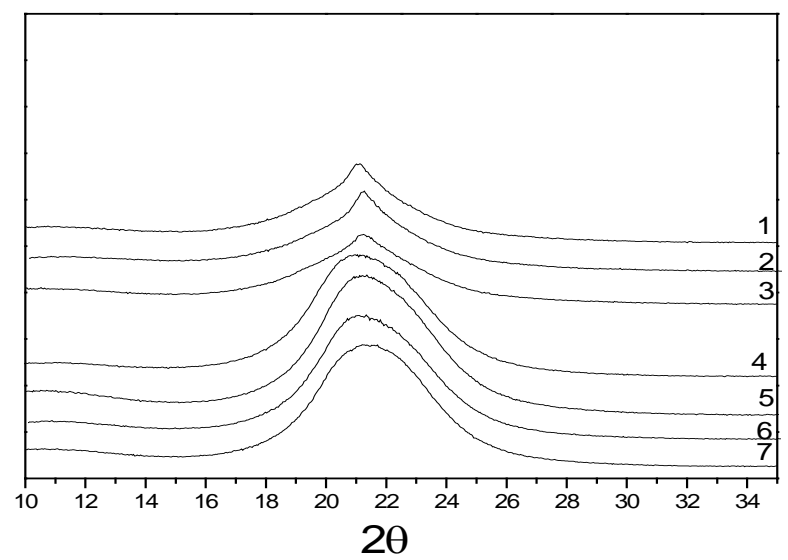

Fig. 6. X-ray diffraction patterns of PA6 at different tensile strain state : (1)1-state;(2)2-state;(3)3-state;(4)4-state;(5)5-state; (6)6-state; (7)7-state

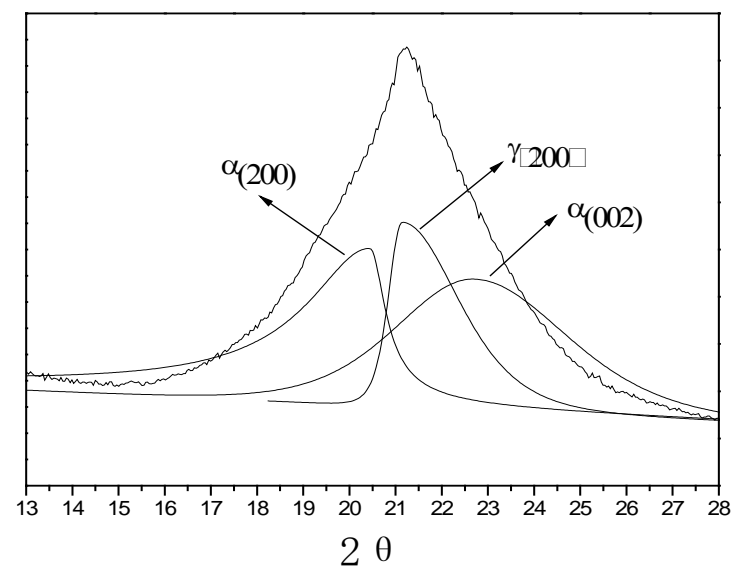

Fig. 7. Deconvolution curves of the X-ray diffraction curve of PA6

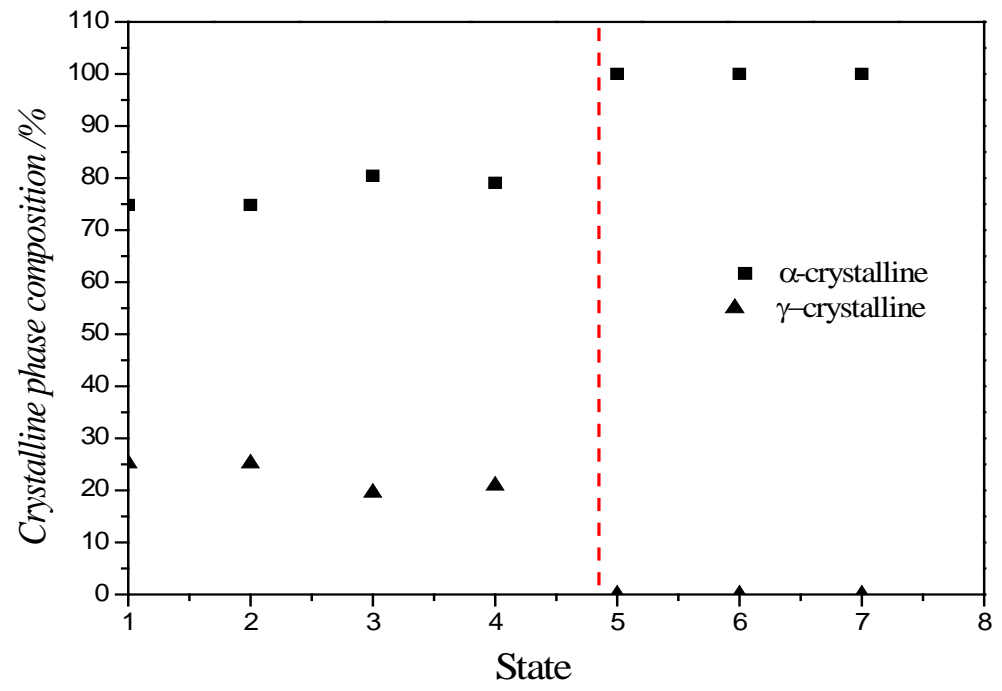

Fig. 8. Change of PA6 crystal structure upon tensile process.

It could be seen that we could do some further research about the change of PA6 crystal structure through the spectrogram of 13C CP/MAS [18-19]. Fig. 9. and Table 2 show that under the tensile stage of 5, the $\gamma$ crystal C2 peak which corresponded to chemical shift $32.3 \mathrm{ppm}$ was disappeared 
basically and under the tensile stage of 1 , the $\gamma$ crystal C1 peak which corresponded to chemical shift $38.5 \mathrm{ppm}$ was less than the signal of tensile state 1 obviously. The conclusions further illustrated the $\gamma$ crystal was gradually disappeared in the process of low tensile rate. Combined with $\mathrm{XRD}$ analysis, we though that the phenomenon of double yield in low-speed tensile process might be accompanied with the destruction of the $\gamma$ crystal.

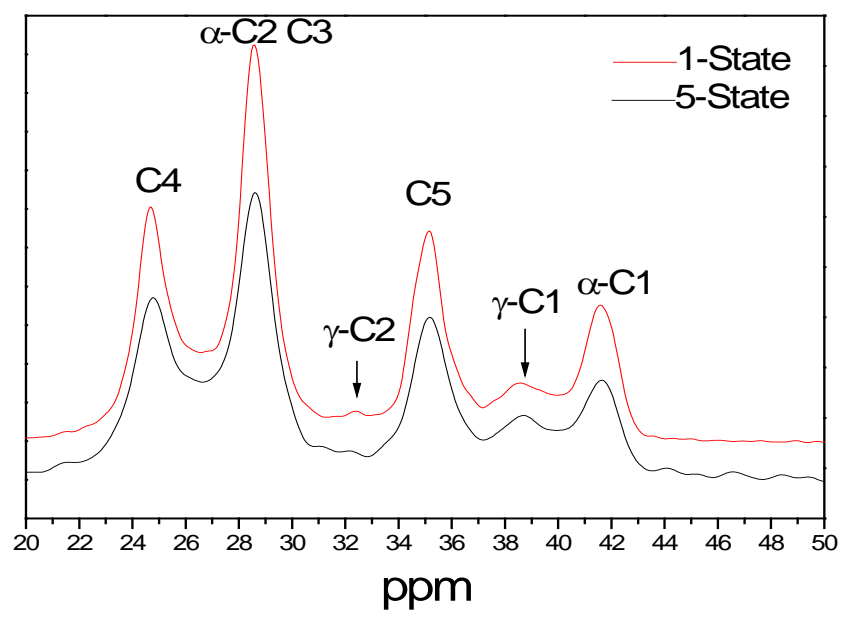

Fig. 9. $\mathrm{CH}_{2}$ resonances of ${ }^{13} \mathrm{C}$ CPMAS spectra of different tensile strain state PA6

Table 2. ${ }^{13} \mathrm{C}$ Chemical Shifts of the Methylene Carbons in aggregation of PA6

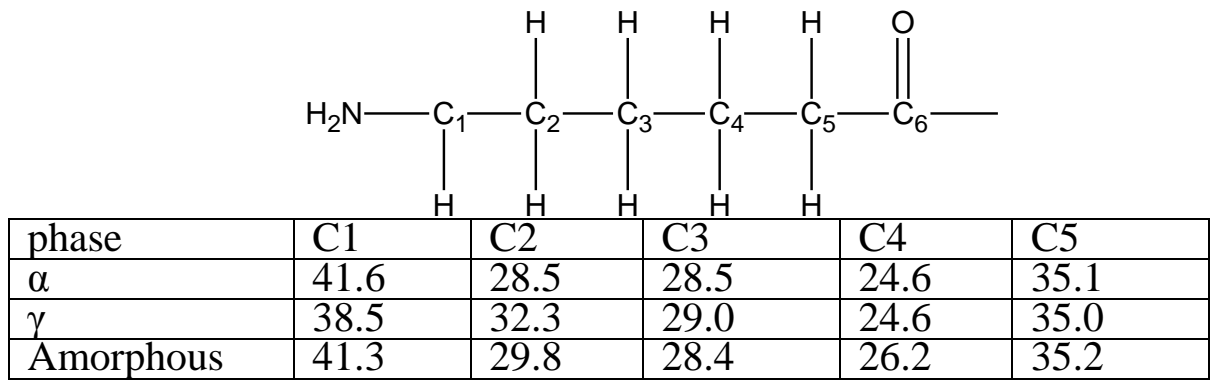

a. In ppm relative to TMS. b. From ref 2:C3,C4 and C4 resonances were not individually assigned by the authors.

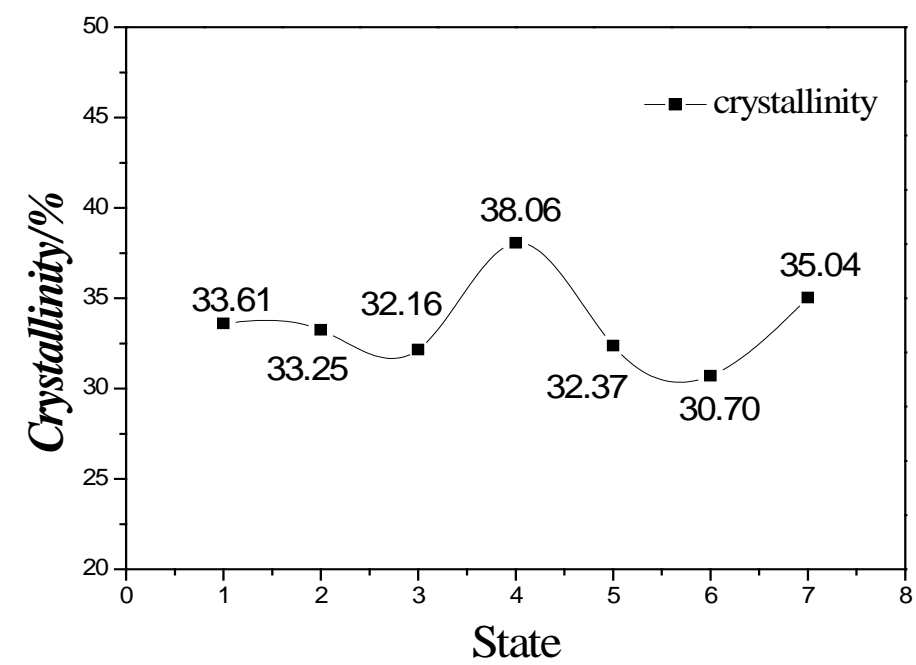

Fig. 10 Change of PA6 crystallinity upon tensile process. 
Fig. 10. shows the changing trend of PA6 crystallinity upon seven tensile processes. The two peak-valleys of crystallinity changing curve just corresponded to the twice tensile states which were yielding. So we thought there was a certain relationship between double yield and crystal destruction. After the first yield, PA6 had experienced partial irreversible plastic deformation and molecular chain orientation arrangement, which caused the increase of crystallinity. In the process of second yield along with the decrease of crystallinity, which because of the obvious damage of the crystal structure, then the crystallinity was increased by the orientation hardening.

\section{Conclusions}

With the increase of tensile rate, the yield strength of PA6 was on the rise, and the elongation at break decreased. The elongation at break declined sharply when the tensile rate increased to 50 $\mathrm{mm} / \mathrm{min}$, it' s because that under the tensile rate was $50 \mathrm{~mm} / \mathrm{min}$, the PA6 crystallinity decreased obviously after stretching, the lattice was damaged seriously, and there was also a sharp decline in the capacity of molecular chain segments together with plastic deformation.

In low-speed PA6 tensile process, when two yield occurred in tensile process, the two peak valleys of seven sates in the crystallinity changing curve just respectively corresponded to the tensile states, we thought there was a certain relationship between double yield and crystal destruction. The phenomenon of double yield in low-speed tensile process might be accompanied with the destruction of the $\gamma$ crystal.

\section{Acknowledgement}

This work was supported by Science and technology cooperation project of Guizhou Province, China (2012-7009); Major projects of Guizhou Province, China(2013-6016); Graduate student education innovation base of Guizhou University, China(CXJD[2014]08)

\section{References}

[1] K.Dijkstra,H.H.Wevers.R.J.Gaymans.Nylon-6/rubber blends: 7. Temperature-time effects in the impact behaviour of nylon/rubber blends [J]. Polymer, 1994, 35(2): 323-331.

[2] J. H. Yang, Y. Zhang, Y. X. Zhang. Brittle-ductile transition of PP/POE blends in both impact and high speed tensile tests [J]. Polymer, 2003, 44:5047-5052.

[3] A. Hassan, B. Haworth. Impact properties of acrylate rubber-modified PVC: Influence of temperature [J].Materials Processing Technology, 2006, 172:341-345.

[4]J. Richeton, S. Ahzi, K. S. Vecchio, et al, Influence of temperature and strain rate on the mechanical behaviour of three amorphous polymers: Characterization and modeling of the compressive yield stress[J].International Journal of Solids and Structures,2006,(43):2318-2335.

[5] A. D. Mulliken, M. C. Boyce. Mechanics of the rate-dependent elastic-plastic deformation of glassy polymers from low to high strain rates[J].International Journal of Solids and Structures, 2006 (43): 1331-1356.

[6] GUO Wei-nan, ZHAO Cai-xia, CHEN Chun-yin, et al. Investigation on the rheological behavior of polyamide 6/POE/EVOH blends [J].Plastics, 2012, 41(1):58-60.

[7] Yongyan Pang, Xia Dong, Kaipeng Liu, et al. Ductile-brittle transition controlled by isothermal crytallization of isotactic polyropylene and its blend with poly(ethlyene-co-octene)[J].Polymer, 2008,(49):4259-4270.

[8] Yuzhu Xiong, Jie Yu, Chaoxian wang. Brittle-ductile transition of PA6/POE-g-MAH blends in notched tensile and notched impact tests [J].Polymer Materials Science and Engineering, 2009, 25(9):117-120. 
[9] XU Tao, YU Jie, LEI Hua, et al. The quantitative description of aggregation structure and the relationship with mechanical properties of PP material [J]. Acta Polymerica sinica, 2001, (1):147-151.

[10] CAI Chang-an. The Strain Rate Sensitivity of Ploybutylene Terephthalate[J]. Journal of Guizhou University of Technology, 2001, 3(30):13-16.

[11] Yu Jie, Le Heqing, Zhang Xiaoyian ,et al. Effects of Temperature and Load Rate on Mechanical Properties of PVC [J].Journal of Guizhou Institute of Technology,1992,1(21):71-76.

[12] FAN Jin-juan, LIU Gao-yuan, ZHANG Ju-hua, et al. Effect of Loading Rate on Tensile Fracture Behavior of Silicon Rubber [J].Materials for Mechanical Engineering,2007,12(31):69-71.

[13] Zhang ChengFeng, Liu YuHai, Liu ShaoXuan, et al. Crystalline behaviors and phase transition during the manufacture of fine denier PA6 fibers [J]. Science China: Part B, 2009, 52(11): 18351842.

[14] Guifang Shan, Wei Yang, Banghu Xie, et al. Double Yielding Behaviors of Polyamide 6 and Glass Bead Flled Polyamide 6 Composites[J]. Polymer Testing, 2005, 24(6):704-711.

[15] M. F. Butlera, A.M. Donald, A. J. Ryanb, Time Resolved Simultaneous Small- and Wide-Angle X-ray Scattering During Polyethylene Deformation-II. Cold Drawing of Linear Polyethylene [J]. Polymer, 1998, 39(1):39-52.

[16] T. A. Waigh, I. Hopkinson, A. M. Donald .et al, Analysis of the Native Structure of Starch Granules with X-ray Microfocus Diffraction[J]. Macromolecules, 1997, 30(13): 3813-3820.

[17] J. C. Ho, K. H. Wei, Induced $\gamma \rightarrow \alpha$ Crystal Transformation in Blends of Polyamide 6 and Liquid Crystalline Copolyester [J]. Macromolecules, 2000, 33(14):5181-5186.

[18] G.. R. Hatfield, J. H. Glans, W. B. Hammond, Characterization of Structure and Morphology in Nylon 6 by Solid-State 13C-NMR and 15N-NMR[J].Macromolecules, 1990,23(6):1654-1658.

[19] R. Schreiber, W. S. Veeman, W. Gabriëlse, J. Arnauts, NMR Investigations of Orientational and Structural Changes in Polyamide 6 Yarns by Drawing [J]. Macromolecules, 1999: 32 (14):4647-4657. 